Ärztliche Erfahrung beschränkt sich nicht auf medizinisches Fachwissen. 100 Euro.

Sie entsteht auch aus den mehr oder minder alltäglichen, heiter, ärgerlich oder nachdenklich stimmenden Erlebnissen mit Patienten, Kollegen und Mitarbeitern. Senden Sie uns Ihre Geschichte an: cornelius.heyer@springer.com.

\title{
Die Cannabis-Aktivistin
}

_ Kernig ist die ältere Dame, die sich heute zum Vorgespräch für eine Akupunkturbehandlung ihrer lästigen Rückenschmerzen bei mir vorstellte. Ich kenne sie seit Jahren und habe wirklich Mitleid mit ihr, weil sie kaum noch in den Schlaf findet.

Heute aber hatte ich ernsthafte Probleme damit, das Grinsen von meinem Gesicht fern zu halten, das sich immer wieder einschleichen wollte. Ich starrte immer nur auf die Mütze, die meine $\mathrm{Pa}$ tientin noch trug, weil sie eben aus der unwirtlichen Kälte hereingeschneit war. Auf der schwarzen Mütze prangte in den typischen rot-gelb-grünen Farben ein MarihuanaBlatt. Sollte es sich bei der freundlichen Seniorin etwa um eine Cannabis-Aktivistin handeln? Eine weibliche Version des Grü-

Manche älteren Herrschaften sollen dem Hanf ja recht zugetan sein.

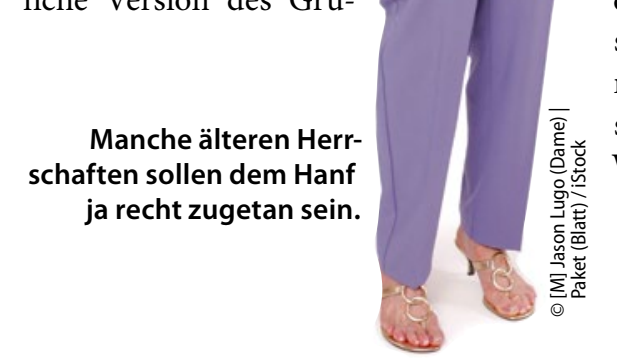

nen-Politikers Hans-Christian Ströbele („Gebt das Hanf frei!“)?

Irgendwann konnte ich mir die Frage nicht mehr verkneifen: „Wissen Sie, was Sie da spazieren tragen? Sind Sie ein Freund des Feierabend-Joints?" Sie schaute mich verständnislos an und lächelte breit, als sie erfuhr, was das hübsche Muster auf ihrer Wintermütze bedeutet. „Die hat mir meine Schwester geschenkt!", sagte sie. Wir beide glauben nicht, dass diese wusste, was sie da verschenkte. Oder doch? Manche stillen Wasser sind ja tief!

Dr. Frauke Höllering, Ansbach

\section{Der Alkoholiker will nur heim zu seinen Mietzen}

_ Im ärztlichen Notdienst wurde ich einmal von der Polizei gebeten, eine Gewahrsamsfähigkeitsuntersuchung bei einem stark Betrunkenen durchzuführen. Dieser langjährige Alkoholiker hatte 1,8 Promille in der Atemluft, war aber in klinisch passablem Zustand, hatte nichts angestellt und sollte in Schutzgewahrsam genommen werden.

Schon bei der körperlichen Untersuchung wollte der Mann zeigen, wer hier der King im Ring ist. Ich ging aber nicht weiter darauf ein. Da er vernehmungsfähig war, wurde nun vorschriftsgemäß der Richter angerufen, der die Schutzgewahrsam anordnen sollte. Der Trinker übernahm am Telefon sofort das Wort und teilte dem Richter mit, dass er nichts angestellt und höchstens ein oder zwei Bier getrunken habe und im Übrigen sofort nach Hause wolle. Auch wies er darauf hin, dass er zu Hause zwei Katzen habe. „Die sind wie Frauen, sie wollen und müssen versorgt werden“, philosophierte er.

Der Richter erklärte, dass der Mann zu seinem eigenen Schutz in Gewahrsam bleiben müsse. Nun steigerte sich der Trinker in Rage. „Haben Sie eine Frau?", schrie er den Richter an, der nicht antwortete. Als der Mann die Frage noch lauter wiederholte, bejahte der Richter sie nach einer kleinen Pause leise. Darauf schrie der Trinker ins Telefon:
„Wollen Sie Ihre Frau versorgen oder nicht?!“Die Umstehenden konnten sich ein heftiges Grinsen nicht verkneifen.

Dem Richter wurde es nun aber auch zu bunt, und er beantwortete diese als Frage formulierte Anklage nicht mehr. Er verlangte nun nach einem Polizisten und teilte diesem mit, dass der Proband zum eigenen Schutz acht Stunden in Gewahrsam genommen werden sollte. Der Betrunkene war mit dem Richter eigentlich noch lange nicht fertig und schimpfte vor sich hin. Erst als er merkte, dass das Objekt seines Zorns schon nicht mehr in der Leitung war, resignierte er und lenkte ein.

Dr. Rainer Hakimi, Stuttgart 